\title{
A licenciatura em Educação do Campo na Universidade Federal do Triângulo Mineiro: território de contradições
}

\author{
Daniele Cristina de Souza ${ }^{1}$, Danilo Seithi Kato ${ }^{2}$, Tânia Halley Oliveira Pinto ${ }^{3}$ \\ ${ }^{1}$ Universidade Federal do Triângulo Mineiro - UFTM. Departamento de Educação em Ciências, Matemática e \\ Tecnologias (DECMT). Avenida Randolfo Borges Júnior 1400, Univerdecidade, Uberaba - MG. \\ Brasil. danieabio@gmai.com. ${ }^{2}$ Universidade Federal do Triângulo Mineiro - UFTM. ${ }^{3}$ Universidade Federal do \\ Triângulo Mineiro - UFTM.
}

RESUMO. Desde o seu surgimento a Licenciatura em Educação do Campo na Universidade Federal do Triângulo Mineiro (UFTM) enfrenta uma série de desafios. Uma das questões posta já a priori é sobre a existência ou não do público alvo, principalmente quanto se o Triângulo Mineiro e o Alto Paranaíba têm demanda para que o curso tenha continuidade. Frente a esta problemática, o presente artigo traz um estudo que visou identificar as demandas formativas, considerando principalmente a dimensão da educação escolar. A perspectiva metodológica é diagnóstica a partir de dados secundários de origem documental. Ao realizar esta análise uma das primeiras contradições que podemos encontrar é referente ao próprio sentido e demarcação do que seja campo, havendo critérios políticos, administrativos e epistemológicos que precisam ser problematizados. Do ponto de vista dos dados encontrados, notamos que a região da abrangência da UFTM possui sim escolas do campo, professores leigos e um cenário de luta pela terra que geralmente é silenciado, desconsiderado e pouco compreendido. Constatamos demandas concretas, não só com relação aos sujeitos, mas também um contexto para investigações que são necessárias para ressignificar os territórios de atuação da universidade.

Palavras-chave: Mapeamento, Ensino Superior, Educação do Campo. 


\title{
Rural Education degree in the Federal University of the Triângulo Mineiro: territory of contradictions
}

\begin{abstract}
Since its establishment the Rural Education degree at the Federal University of the Triângulo Mineiro (UFTM) is facing a number of challenges. One of the previously questions is about the existence or not of the target audience, mainly if the Triângulo Mineiro and Alto Paranaíba have requirement for the course to continue. In this context, the present article presents a study that aimed to identify the training demands, considering above all the dimension of school education. The methodological perspective is diagnostic based on secondary data in a documental analysis. Carrying out this analysis, one of the first discrepancies that we can find is about the own meaning and demarcation of what is the field, within political, administrative and epistemological criteria that need to be problematized. The data suggest that the UFTM's region has, indeed, rural schools, lay teachers, and a struggle for land scenario that is usually silenced, obliterated and poorly understood. Concrete demands were found, not only with regard to the subjects, but also a context for further investigations required to give a new meaning to the territories of university performance.
\end{abstract}

Keywords: Mapping, Higher Education, Rural Education. 


\section{Grado en el Educación del Campo en la Universidade Federal do Triângulo Mineiro: un territorio de contradiciones}

RESUMEN. Desde su inicio la Licenciatura en Educación del Campo en la Universidade Federal de Triângulo Mineiro (UFTM) enfrenta varios retos. Una de las preguntas es acerca de si hay o no público, se el Triángulo Mineiro y Alto Paranaíba tienen demanda para que el curso tenga continuidad. Frente a este problema, este trabajo presenta un estudio destinado a identificar las necesidades de formación, especialmente teniendo en cuenta la dimensión de la educación escolar. El enfoque metodológico es diagnóstico, un análisis documental con datos secundario. Mediante la realización de este análisis una de las primeras contradicciones que podemos encontrar se relaciona con el sentido y la demarcación de lo terreno, con criterios políticos, administrativos y epistemológicos que necesitan ser problematizado. Desde el punto de vista de los datos que se encuentran, observamos que el área de cobertura de UFTM tiene lugar para el curso en el ámbito de las escuelas, los profesores sin formación superior, y una escena de lucha por la tierra que por lo general es silenciado, ignorado y poco conocida. Se han encontrado exigencias prácticas, no sólo con respecto los sujetos del campo, sino también un contexto para las investigaciones que son necesarias para replantear los territorios de actuación de la universidad.

Palabras clave: Cartografía, Enseñanza Superior, Educación del Campo. 


\section{Introdução}

A Educação do Campo recebe considerável atenção por parte das políticas públicas com a participação de instituições que visam contribuir para a formação do cidadão do campo, levando em consideração às populações rurais em suas mais variadas formas de produção da vida. Ela nasce como contraponto ao silêncio do Estado e às propostas da chamada educação rural ou educação para o meio rural no Brasil. Suas raízes estão na trajetória da Educação Popular e nas lutas sociais da classe trabalhadora do campo (Santos, Paludo \& Oliveira, 2010).

A Educação do Campo na década de 1990 é caracterizada pela oposição aos projetos cuja visão instrumentalizadora da educação é colocada a serviço das demandas de um determinado modelo de desenvolvimento do campo, exploratório, excludente e desigual. Sendo assim, procura-se construir uma educação enquanto formação humana, omnilateral. Portanto, a educação do campo se afirma como uma educação emancipatória, vinculada a um projeto histórico para construção de uma nova forma de organização das relações sociais, econômicas, políticas e culturais se contrapondo à forma atual de organização e de relações, que é a capitalista (Santos, Paludo \& Oliveira, 2010).

É no início do século XXI e nos últimos anos que a educação do campo ganha especial atenção pelo Estado. As diretrizes operacionais para a educação básica das escolas do campo trazidas na Resolução de 2002, complementadas e ratificadas na resolução de 2008, a partir das quais é apresentado um conjunto de princípios e procedimentos que visam adequar o projeto institucional das escolas do campo às orientações oficiais para a educação básica e para a formação de professores de nível médio. Nota-se, portanto, toda uma regulamentação a nível federal da educação do campo. O que é reforçado em 2010 com a homologação das Diretrizes Curriculares Nacionais da Educação Básica (Resolução $\mathrm{n}^{\circ}$ 04/2010/CEB/CNE) a Educação do Campo passa a ser reconhecida como modalidade de ensino e, com o Decreto no 7.352/2010 é instituída a Política de Educação do Campo e o Programa Nacional de Educação na Reforma Agrária PRONERA.

Em março de 2012 foi instituído o Programa Nacional de Educação do Campo - PRONACAMPO, que disciplina ações específicas de apoio à Educação do Campo e à educação quilombola, considerando as reivindicações históricas 
destas populações quanto à efetivação do direito à educação. A partir deste programa um edital público viabilizou a abertura de 40 cursos de Licenciatura de Educação do Campo nas Universidades Federais do país, o curso de Licenciatura de Educação do Campo da Universidade Federal do Triângulo Mineiro está entre estes.

Estes cursos de licenciatura vêm a se somar nas ações afirmativas que visam contribuir para a superação de muito dos desafios históricos para a consolidação de uma educação que contemple uma formação humana plena e crítica nas escolas do campo. Dentre os desafios podemos citar a desvalorização do meio rural, colocado como um território atrasado e a ser superado pela cidade; o que é refletido em políticas de diluição ou descaracterização das escolas em funcionamento nos espaços rurais, com o fechamento de muitas delas, transportando os alunos para escolas distantes no ambiente urbano; ou ainda a intensa desvalorização dos saberes populares provenientes destes. Outro grande desafio é a constatação da falta de estrutura de muitas escolas do campo, não só de estrutura física e material e de investimentos, mas de profissionais qualificados.

Há historicamente uma desvalorização e silenciamento das necessidades do campo, assim como uma desvalorização dos direitos dos sujeitos do campo, sua cultura e forma de produção e reprodução da vida. A política PROCAMPO foi um meio para contribuir com a superação deste cenário, visando tensionar uma resposta social às reivindicações das populações do campo. Todavia, os resultados do silenciamento nas políticas públicas e mesmo nas produções acadêmicas continuam impactando a visão que temos sobre o campo e sobre a educação do/no campo.

Neste sentido, o objetivo deste estudo é identificar as demandas formativas que a Universidade Federal do Triângulo Mineiro pode contemplar no âmbito da formação de professores para a educação do campo, considerando principalmente a dimensão da educação escolar.

A perspectiva metodológica do estudo aqui apresentado é diagnóstica a partir de dados secundários proveniente de pesquisa realizada pelo Núcleo de Processo Seletivo Discente - NUPE/UFTM - 2015, dados do Censo Escolar, IBGE, Pesquisa Data Luta, Plataforma Cultiveduca, etc. A partir dos indicadores quantitativos procuraremos realizar uma caracterização inicial, principalmente da região do Triângulo Mineiro e Alto Paranaíba, assim como municípios do Noroeste do Estado 
de São Paulo, visto que este território abarca a maior quantidade de matrículas na Universidade Federal do Triângulo Mineiro (UFTM).

O recorte territorial também foi feito buscando delimitar um espaço que viabilize, do ponto de vista logístico e orçamentário, a realização dos tempos formativos da Licenciatura em Educação do Campo (tempo escola e tempo comunidade). Tais tempos-espaços são intercalados por momentos presenciais na Universidade (tempo escola) e períodos nas comunidades (tempo comunidade). Durante a realização das atividades em suas comunidades os estudantes têm a visita e acompanhamento dos docentes, em sequência retornam para a Universidade, contemplando assim a Alternância. A pedagogia da alternância é um dos pilares pedagógico e metodológico da formação do professor/educador do campo, sendo essencial a sua garantia.

\section{A abrangência da UFTM e as demandas formativas para a educação do campo}

De acordo com o documento que traz a análise comparativa dos ingressos por vestibular e SISU na UFTM, nos primeiros semestres dos anos de 2014 e 2015, os municípios do Triângulo Mineiro que apresentaram ingressantes foram:
Araguari, Araxá, Campo Florido, Conceição das Alagoas, Delta, Ibiá, Ituiutaba, Iturama, Monte Carmelo, Nova Ponte, Patrocínio, Patos de Minas, Sacramento, Uberaba, Uberlândia, Veríssimo (Tabela 1).

A delimitação geográfica adotada para o território denominado Triângulo Mineiro e Alto Paranaíba foi criada pelo Instituto Brasileiro de Geografia e Estatística - IBGE (1990), sendo composta pelas 7 microrregiões (Ituiutaba, Uberlândia, Patrocínio, Patos de Minas, Frutal, Uberaba e Araxá) com um total de 66 municípios.

Como é possível notar nos dados do NUPE/UFTM (Tabela 1), apenas 16 municípios do Triângulo Mineiro e Alto Paranaíba estão representados, com ingresso de 871 estudantes. Não houve nenhum ingresso dos demais 50 municípios desta região, o que coloca um questionamento sobre os motivos desta ausência e se tais municípios possuem demandas no que concerne à formação de professores do campo. Por sua vez, 12 municípios do noroeste do Estado de São Paulo tiveram ingressantes na UFTM totalizando 415 estudantes. 
Tabela 1. Número de matrículas na UFTM por município de origem.

\begin{tabular}{|c|c|c|c|}
\hline \multicolumn{2}{|c|}{ Município de Origem } & \multirow{2}{*}{$\begin{array}{c}\text { Estado } \\
\text { MG }\end{array}$} & \multirow{2}{*}{$\begin{array}{c}\mathrm{N}^{\circ} \text { de estudantes ingressantes na } \\
\text { UFTM nos primeiros semestres } \\
\text { de } 2014 \text { e } 2015 \\
4\end{array}$} \\
\hline 1 & Araguari & & \\
\hline 2 & Aramina & SP & 7 \\
\hline 3 & Araraquara & SP & 30 \\
\hline 4 & Araxá & MG & 47 \\
\hline 5 & Belo Horizonte & MG & 13 \\
\hline 6 & Campo Florido & MG & 7 \\
\hline 7 & Conceição das Alagoas & MG & 5 \\
\hline 8 & Delta & MG & 2 \\
\hline 9 & Divinópolis & MG & 7 \\
\hline 10 & Franca & SP & 100 \\
\hline 11 & Guaíra & SP & 19 \\
\hline 12 & Ibiá & MG & 3 \\
\hline 13 & Igarapava & SP & 24 \\
\hline 14 & Ituiutaba & MG & 9 \\
\hline 15 & Iturama & MG & 14 \\
\hline 16 & Ituverava & $\mathrm{SP}$ & 23 \\
\hline 17 & Monte Carmelo & MG & 3 \\
\hline 18 & Nova Ponte & MG & 2 \\
\hline 19 & Patos de Minas & MG & 7 \\
\hline 20 & Patrocínio & MG & 7 \\
\hline 21 & Ribeirão Preto & $\mathrm{SP}$ & 124 \\
\hline 22 & Sacramento & MG & 16 \\
\hline 23 & São Carlos & SP & 16 \\
\hline 24 & São Joaquim da Barra & SP & 15 \\
\hline 25 & São José do Rio Preto & SP & 28 \\
\hline 26 & São Paulo & SP & 15 \\
\hline 27 & Sertãozinho & SP & 14 \\
\hline 28 & Uberaba & MG & 661 \\
\hline 29 & Uberlândia & MG & 62 \\
\hline 30 & Veríssimo & MG & 2 \\
\hline & TOT & & 1286 \\
\hline
\end{tabular}

Fonte: NUPE/UFTM - 2015.

Na tabela 2 está sistematizada a população estimada para os municípios do Triângulo Mineiro e Alto Paranaíba, assim como a indicação do número de escolas da rede estadual consideradas como do campo pela Secretaria de Educação de Minas Gerais (SEE-MG) com suas respectivas
Superintendências Regionais de Ensino responsáveis.

Os dados da tabela 2 indicam que os municípios são pequenos, o que pelo critério demográfico (menos de 50 mil habitantes) permitiria que tais municípios fossem enquadrados como 
predominantemente rural o que por sua vez, permitiria que as escolas localizadas nesses municípios também fossem classificadas como do campo. Porém, o que se nota é que dos 58 municípios que se enquadram como rural, por meio do critério demográfico, apenas 9 deles apresentam escolas do campo. Sabemos que o zoneamento das cidades considera critérios administrativos a partir dos quais são delimitados o espaço rural e o urbano. A delimitação do rural se faz pela exclusão a partir da delimitação do espaço que é considerado urbano, ou seja, o que não for urbano é rural, o que expressa o desafio de delimitar a ruralidade na região, e mesmo no país como um todo. Essa delimitação do que é rural e urbano provoca contradições interessantes, como por exemplo, o fato de que dentre o total de 19 escolas elencadas pela SEE-MG como sendo do campo, 10 delas estarem localizadas em municípios com mais de 50 mil habitantes.

Tabela 2. Estimativa populacional dos municípios do Triângulo Mineiro e Alto Paranaíba e o número de escolas estaduais consideradas do campo por município, com data de referência de $1^{\circ}$ de Julho de 2014.

\begin{tabular}{|c|c|c|c|c|}
\hline & Município & $\begin{array}{c}\text { População } \\
\text { Estimada }\end{array}$ & $\begin{array}{l}\text { Escolas do } \\
\text { campo } \\
\text { segundo a } \\
\text { SEE-MG }\end{array}$ & $\begin{array}{c}\text { Superintendências } \\
\text { Regionais de } \\
\text { Ensino }\end{array}$ \\
\hline 1 & Cachoeira Dourada & 2.645 & 0 & Ituiutaba \\
\hline 2 & Canápolis & 11.945 & 0 & Ituiutaba \\
\hline 3 & Capinópolis & 16.038 & 0 & Ituiutaba \\
\hline 4 & Centralina & 10.593 & 0 & Ituiutaba \\
\hline 5 & Gurinhatã & 6.094 & 1 & Ituiutaba \\
\hline 6 & Ipiaçu & 4.260 & 0 & Ituiutaba \\
\hline 7 & Ituiutaba & 102.690 & 0 & Ituiutaba \\
\hline 8 & Santa Vitória & 19.250 & 0 & Ituiutaba \\
\hline 9 & Abadia dos Dourados & 6.992 & 0 & Monte Carmelo \\
\hline 10 & Cascalho Rico & 3.018 & 0 & Monte Carmelo \\
\hline 11 & Coromandel & 28.428 & 2 & Monte Carmelo \\
\hline 12 & Douradoquara & 1.915 & 0 & Monte Carmelo \\
\hline 13 & Estrela do Sul & 7.851 & 0 & Monte Carmelo \\
\hline 14 & Grupiara & 1.415 & 0 & Monte Carmelo \\
\hline 15 & Monte Carmelo & 47.770 & 0 & Monte Carmelo \\
\hline 16 & Romaria & 3.664 & 0 & Monte Carmelo \\
\hline 17 & Carmo do Paranaíba & 30.739 & 0 & Patos de minas \\
\hline 18 & Lagoa Formosa & 17.962 & 1 & Patos de minas \\
\hline 19 & Matutina & 3.853 & 0 & Patos de minas \\
\hline 20 & Patos de Minas & 147.614 & 1 & Patos de minas \\
\hline 21 & Rio Paranaíba & 12.364 & 0 & Patos de minas \\
\hline 22 & Santa Rosa da Serra & 3.357 & 0 & Patos de minas \\
\hline
\end{tabular}




\begin{tabular}{|c|c|c|c|c|}
\hline 23 & São Gotardo & 34.107 & 0 & Patos de minas \\
\hline 24 & Tiros & 6.912 & 0 & Patos de minas \\
\hline 25 & Arapuá & 2.870 & 0 & Patos de Minas \\
\hline 26 & Cruzeiro da Fortaleza & 4.122 & 0 & Patrocínio \\
\hline 27 & Guimarânia & 7.764 & 0 & Patrocínio \\
\hline 28 & Ibiá & 24.613 & 0 & Patrocínio \\
\hline 29 & Iraí de Minas & 6.842 & 1 & Patrocínio \\
\hline 30 & Patrocínio & 87.928 & 4 & Patrocínio \\
\hline 31 & Perdizes & 15.484 & 2 & Patrocínio \\
\hline 32 & Serra do Salitre & 11.236 & 0 & Patrocínio \\
\hline 33 & Água Comprida & 2.067 & 0 & Uberaba \\
\hline 34 & Araxá & 101.136 & 0 & Uberaba \\
\hline 35 & Campo Florido & 7.562 & 0 & Uberaba \\
\hline 36 & Campos Altos & 15.078 & 0 & Uberaba \\
\hline 37 & Carneirinho & 9.939 & 0 & Uberaba \\
\hline 38 & Comendador Gomes & 3.105 & 0 & Uberaba \\
\hline 39 & Conceição das Alagoas & 25.588 & 0 & Uberaba \\
\hline 40 & Conquista & 6.860 & 0 & Uberaba \\
\hline 41 & Delta & 9.280 & 0 & Uberaba \\
\hline 42 & Fronteira & 16.036 & 0 & Uberaba \\
\hline 43 & Frutal & 57.269 & 1 & Uberaba \\
\hline 44 & Itapagipe & 14.645 & 1 & Uberaba \\
\hline 45 & Iturama & 37.277 & 0 & Uberaba \\
\hline 46 & Limeira do Oeste & 7.327 & 0 & Uberaba \\
\hline 47 & Pedrinópolis & 3.638 & 0 & Uberaba \\
\hline 48 & Pirajuba & 5.396 & 0 & Uberaba \\
\hline 49 & Planura & 11.355 & 0 & Uberaba \\
\hline 50 & Pratinha & 3.485 & 0 & Uberaba \\
\hline 51 & Sacramento & 25.432 & 0 & Uberaba \\
\hline 52 & Santa Juliana & 12.702 & 0 & Uberaba \\
\hline 53 & São Francisco de Sales & 6.110 & 0 & Uberaba \\
\hline 54 & Tapira & 4.484 & 0 & Uberaba \\
\hline 55 & Uberaba & 318.813 & 2 & Uberaba \\
\hline 56 & União de Minas & 4.486 & 0 & Uberaba \\
\hline 57 & Veríssimo & 3.781 & 0 & Uberaba \\
\hline 58 & Araguari & 115.632 & 1 & Uberlândia \\
\hline 59 & Araporã & 6.593 & 0 & Uberlândia \\
\hline 60 & Campina Verde & 19.991 & 1 & Uberlândia \\
\hline 61 & Indianópolis & 6.632 & 0 & Uberlândia \\
\hline 62 & Monte Alegre de Minas & 20.728 & 0 & Uberlândia \\
\hline 63 & Nova Ponte & 14.241 & 0 & Uberlândia \\
\hline 64 & Prata & 27.293 & 0 & Uberlândia \\
\hline 65 & Tupaciguara & 25.269 & 0 & Uberlândia \\
\hline 66 & Uberlândia & 654.681 & 1 & Uberlândia \\
\hline
\end{tabular}

\begin{tabular}{|l|l|l|l|l|l|l|l|}
\hline Rev. Bras. Educ. Camp. & Tocantinópolis & v. 2 & n. 1 & p. 411-435 & jan./jun. & 2017 & ISSN: 2525-4863 \\
\hline
\end{tabular} 
Fontes: Estimativas populacionais, fonte IBGE - Diário Oficial da União de 28 de agosto de 2014. Dados das Escolas do Campo pertencentes à rede estadual de ensino de MG, fonte SEE-MG/2016.

Há muitas controvérsias no que se refere a demarcar o país enquanto principalmente urbano conforme problematização e proposição trazida em Valadares (2014). O autor argumenta da necessidade de que sejam considerados outros critérios além do demográfico e administrativo para caracterizar os municípios, visto que são ainda elementos que se baseiam em decretos de meados do século XX e representam a histórica exclusão e silenciamento dos diretos dos povos do campo. Sem considerar que a delimitação do perímetro urbano é móvel e depende muito do crescimento da população, assim em um censo em que uma família pode estar inserida em uma zona rural, no próximo ela pode ser considerada urbana, mesmo sem qualquer alteração espacial e de inserção no município.

Os processos pelos quais esta divisão se estabelece, assim como os objetivos a que ela atende, caracterizam, em um primeiro nível, o espaço rural como um espaço de exclusão: ao projetar a área de expansão das zonas urbanas, a lei do perímetro urbano não faz senão delimitar, no território, a área no interior da qual os governos estaduais e municipais comprometem-se a instalar equipamentos e serviços de infraestrutura necessários à garantia de qualidade de vida da população - e que, no mais das vezes, constituem direitos sociais básicos, como acesso a serviços de saúde e educação. O rural corresponde precisamente à área excluída desta circunscrição, ou seja, à área não contemplada pela política de planejamento do município (Valadares, 2014, p.8).

\section{O campo na região de predominante abrangência da UFTM: educação do campo para os sujeitos do campo e no campo}

Além dos dados propriamente escolares e demográficos da região do Triângulo Mineiro e Alto Paranaíba, outras fontes precisam ser consideradas para que a complexidade da inserção da educação do campo seja identificada.

A formação de educadores do campo visa contemplar uma demanda de profissionais para atuarem em contextos educativos que viabilize aos sujeitos do campo uma educação contextualizada, que supere a educação rural e que não seja urbanocêntrica. Além do mais, uma educação que não retire os sujeitos do campo para estudar na cidade. Uma educação que fortaleça as escolas do campo existentes e não o seu fechamento. Mas quem são os sujeitos que a educação do campo procura atender? Responder tal questão exige uma diversidade de olhares e consideração dos diversos territórios e 
formas de expressão da ruralidade em um país como o Brasil, extenso em seu tamanho e diversidade cultural. Ademais, a relação campo-cidade precisa ser problematizada tanto no que concerne a maneira como a mesma é trabalhada teoricamente pela ciência, mas principalmente como ela é utilizada nas políticas públicas.

A região do Triângulo Mineiro, embora no discurso cotidiano seja encarada como urbana, é caracterizada por diversas expressões da ruralidade, tais como alguns processos sociais que fazem parte da luta pela terra e a reforma agrária. Além disso, embora nos municípios menores haja predominância da população residindo em áreas urbanizadas, conforme destacam Araujo \& Chelotti (2013, p. 235), "devemos considerar ainda que a maior parte dessas pessoas reproduzem suas vidas na zona rural, nas atividades de lazer, trabalho e no convívio em família”.

Para a análise aqui realizada adotouse o critério desenvolvido no relatório realizado pelo Instituto Brasileiro de Geografia e Estatística (2015). Neste documento o contexto rural é discutido em uma perspectiva distinta de concepções anteriores, que consideravam o campo como um espaço atrasado, em que o tempo corria no ritmo da natureza e não das máquinas, e com tradições estáveis de povos, de certa forma, isolados do mundo urbano globalizado. Ao contrário desta visão, nesse documento é discutida a necessidade de novas pesquisas com esforços em buscar parâmetros mais condizentes com a realidade do campo na atualidade: moderno, altamente tecnológico, industrial e economicamente articulado aos grandes centros comerciais.

Nesse sentido, o referido órgão governamental mune-se dos conceitos de "território-rede" e "território-zona" de Veltz (1999) e Haesbaert (2005), em que os fluxos que compõem as relações de trabalho e economia na relação cidadecampo são os critérios centrais para determinação das regiões rurais. A partir da influência de grandes corporações e sua rede de produção em diferentes espaços, traça-se de uma divisão social do trabalho que delimita as diferentes regiões.

Já os territórios-zona são compreendidos nos referidos documentos como o uso agrícola que se faz do território, incluindo as grandes extensões de terras destinadas a grupos específicos, como é o caso das demarcações indígenas, e outros grupos culturalmente marginalizados da estrutura fundiária brasileira.

Essa definição tende a diminuir a dicotomia cidade/campo buscando critérios mais complexos que àqueles 
historicamente utilizados e que geraram dados demasiadamente enviesados, tal como a ideia de que o meio rural estava em vias de desparecimento das pesquisas censitárias. Anteriormente, o IBGE considerava como município rural àquele com número inferior a 50.000 habitantes. Em muitos municípios com atividades econômicas voltadas à produção agrícola, observou-se um crescimento vultuoso no número de habitantes ultrapassando os 50 mil habitantes, sendo assim, muitos municípios deixaram de ser considerados rurais mesmo que suas atividades econômicas estivessem ligadas à produção agrícola. Isso gerou a ideia errônea de que a vida no campo estava diminuindo progressivamente.

No relatório do ano de 2015 foram delimitadas 144 áreas rurais a partir dos critérios anteriormente descritos. $\mathrm{O}$ Triângulo Mineiro pode ser visto como uma macrorregião com municípios de médio e pequeno porte que apresentam uma rede de relações entre cidades do entorno na estrutura produtiva de grandes empresas da agroindústria. Há uma descentralização da administração, condicionamento, distribuição e cultivo de commodities proporcionando uma base rizomática para os fluxos de produtos e serviços que condicionam uma relação complexa entre campo e cidade.
Dessa forma, é importante considerar a distribuição social do trabalho e suas translações sobre a centralidade da produtividade agrícola,

e consequentemente uma demanda de populações campesinas com um contexto sociocultural próprio e que exigem formação específica. Os municípios de Uberaba e Uberlândia apresentam-se como polos agregadores de grandes agroindústrias, o que influencia na produção, trabalho, ou em outras palavras, nos traços de ruralidade que constituem a sociedade desta macrorregião.

Ademais a estas caracterizações, uma forma de identificar expressões de sujeitos do campo que estejam diretamente vinculados à luta pela terra é mapear os acampamentos e assentamentos existentes. Neste contexto, a partir do "Banco de Dados da Luta pela Terra: Relatório Brasil 2014" (Girardi, 2015) é possível identificar que o Triângulo Mineiro possuía 238 ocupações contabilizadas no período de 1990 a 2014 (Figura 1).

Os dados da Figura 1 evidenciam cerca de dez ocupações em Uberaba-MG no período de 1990 a 2014, com 460 famílias alocadas nestas ocupações. Além disso, nota-se o vultuoso número de famílias e ocupações nas regiões do entorno do município, como por exemplo Uberlândia, com quase 60 ocupações no 
mesmo período e 8.635 famílias

campesinas vivendo nestes locais.

Figura 1. Triângulo Mineiro - Número de ocupações e pessoas por município, período de 1990-2014.

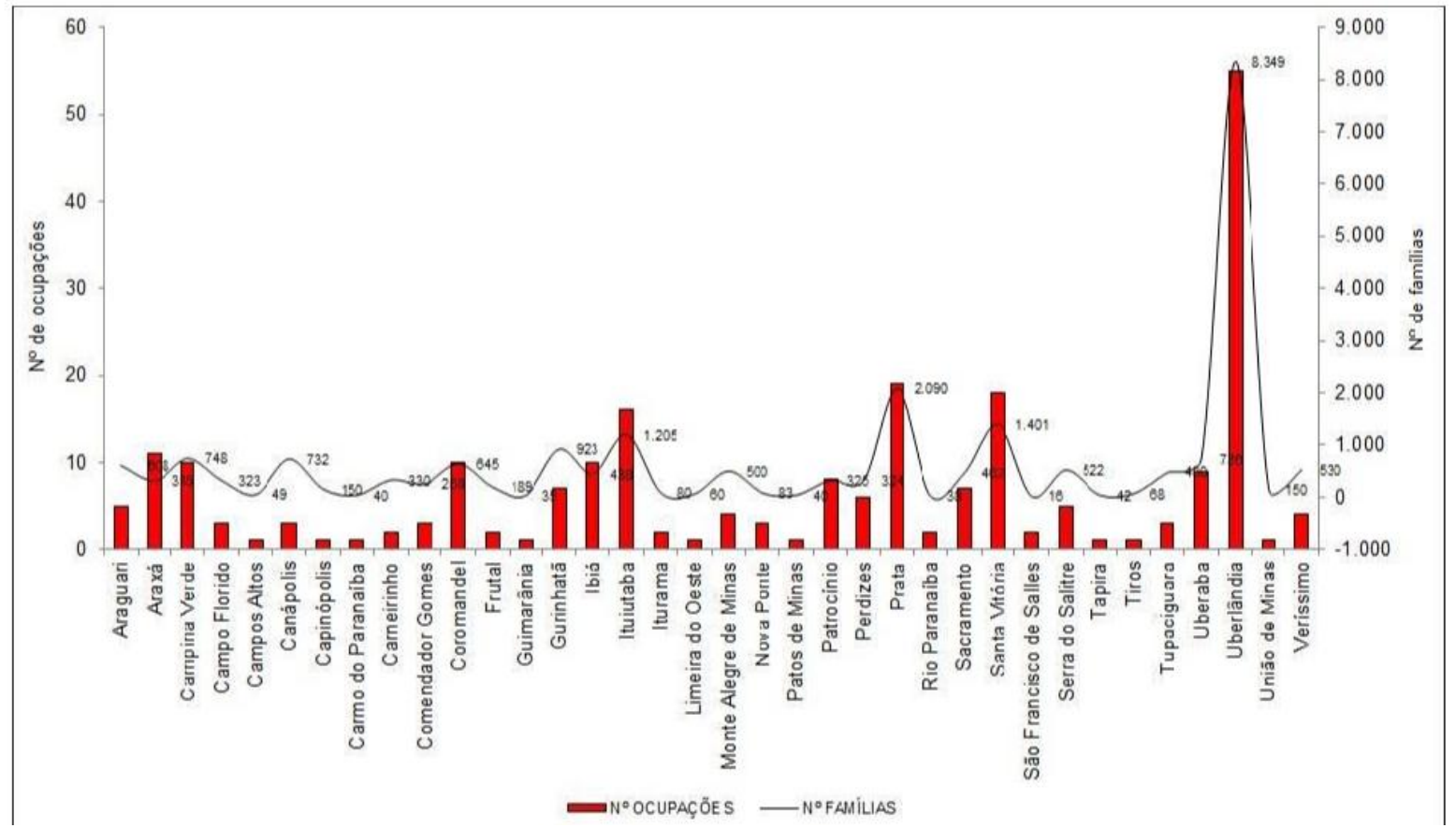

Fonte: DATALUTA - Banco de Dados de Luta Pela Terra, 2014.

Municípios como Campo Florido, Araxá, Campina Verde, Prata, Perdizes e Sacramento são consideradas cidades rurais pelos critérios do IBGE, e já possuem moradores desta região que são atendidos pelo curso de Licenciatura em Educação do Campo da UFTM. A maior parte destes estudantes é proveniente dessas ocupações em área agricultáveis. Dessa forma, considerando a microrregião do município de Uberaba-MG e seu entorno podemos analisar a demanda pela Educação do Campo a partir do número de ocupações e famílias que vivem no campo e que tem relação com os movimentos sociais ligados à luta pela terra. Importante salientar que foram contabilizadas cerca de 20 famílias em uma única ocupação no município de Uberaba no ano de 2014, como evidenciado na Figura 2. 
Figura 2. Triângulo Mineiro - Número de Famílias em Ocupações por Município. 2014.

\begin{tabular}{c|c|c}
\hline MUNICíPIO & No FAMÍLIAS $^{\text {No }}$ & N OCUPAÇÕES \\
\hline Monte Alegre de Minas & 10 & 1 \\
Uberaba & 20 & 1 \\
Uberlândia & 14 & 1 \\
\hline Total & $\mathbf{4 4}$ & $\mathbf{3}$ \\
\hline
\end{tabular}

Fonte: DATALUTA - Banco de Dados da Luta pela Terra, 2014.

Já os municípios de Uberlândia e Monte Alegre de Minas apontam 24 famílias no total para ocupações no mesmo período. O dado evidencia, mais uma vez, a relevante demanda por uma formação que considere o contexto sociocultural da realidade do campo, e não uma Educação da zona urbana para o campo. A comunidade que vive do trabalho agrícola, bem como nas participações ativas em movimentos sociais, demanda uma pedagogia própria, que considere a realidade de vivências dessa população tanto no âmbito temporal quanto na abordagem pedagógica; em suma uma
"Pedagogia do Movimento" (Caldart, 2009).

A partir do número de ocupações e famílias presentes no Triângulo Mineiro é possível vislumbrar a constituição dos chamados "assentamentos", que são estruturas fundiárias oriundas da organização política dos movimentos sociais na distribuição das famílias nos territórios ocupados. A Figura 3 apresenta o número de assentamentos e famílias por município dessa macrorregião, classificando-os em ordem decrescente. 
Figura 3. Triângulo Mineiro- assentamentos rurais por município, período de 1986-2014.

\begin{tabular}{|c|c|c|c|}
\hline CLASS. & MUNICÍPIO & $\mathbf{N}^{\circ}$ ASSENTAMENTOS & $\mathbf{N}^{\circ}$ FAMILIAS \\
\hline $1^{\circ}$ & Uberlândia & 14 & 815 \\
\hline $2^{\circ}$ & Campina Verde & 12 & 630 \\
\hline \multirow{2}{*}{$3^{\circ}$} & Ituiutaba & 6 & 209 \\
\hline & Santa Vitória & 6 & 299 \\
\hline \multirow{2}{*}{$4^{\circ}$} & Ibia & 5 & 159 \\
\hline & Perdizes & 5 & 220 \\
\hline \multirow{2}{*}{$5^{\circ}$} & Prata & 5 & 438 \\
\hline & Gurinhatã & 4 & 218 \\
\hline \multirow{5}{*}{$6^{\circ}$} & Uberaba & 3 & 108 \\
\hline & Veríssimo & 3 & 142 \\
\hline & Araguari & 2 & 100 \\
\hline & Campo Florido & 2 & 153 \\
\hline & Coromandel & 2 & 72 \\
\hline \multirow{8}{*}{$7^{\circ}$} & Limeira do Oeste & 2 & 331 \\
\hline & Patos de Minas & 2 & 102 \\
\hline & Patrocínio & 2 & 90 \\
\hline & Rio Paranaíba & 2 & 33 \\
\hline & São Francisco de Sales & 2 & 30 \\
\hline & Campos Altos & 1 & 24 \\
\hline & Comendador Gomes & 1 & 94 \\
\hline & Nova Ponte & 1 & 11 \\
\hline \multirow{6}{*}{$8^{\circ}$} & Sacramento & 1 & 27 \\
\hline & Serra do Salitre & 1 & 37 \\
\hline & Tapira & 1 & 21 \\
\hline & Tupaciguara & 1 & 177 \\
\hline & União de Minas & 1 & 96 \\
\hline & Total & 87 & 4.636 \\
\hline
\end{tabular}

Fonte: DATALUTA - Banco de Dados da Luta pela Terra, 2014.

O município de Uberaba-MG aparece em sexto lugar com três assentamentos nos últimos 18 anos. Este número equivale a 108 famílias que vivem nestes assentamentos, desempenhando atividades econômicas, sociais e culturais próprias desta organização política, pautada na coletividade e transformação social, dos movimentos sociais. Importante salientar que os assentamentos já estão em processo de legalização das propriedades.
Assim, não pode ser considerado algo intermitente ou temporário, pois os assentados já possuem o aval das instituições governamentais competentes para a produção e permanência de suas famílias nas glebas.

No total são 4.636 assentamentos no Triângulo Mineiro. O gráfico seguinte (Figura 4) evidencia a proporção de assentamentos por município no período de 1986 a 2014. 
Figura 4. Assentamentos Rurais por Município no período de 1986-2014.

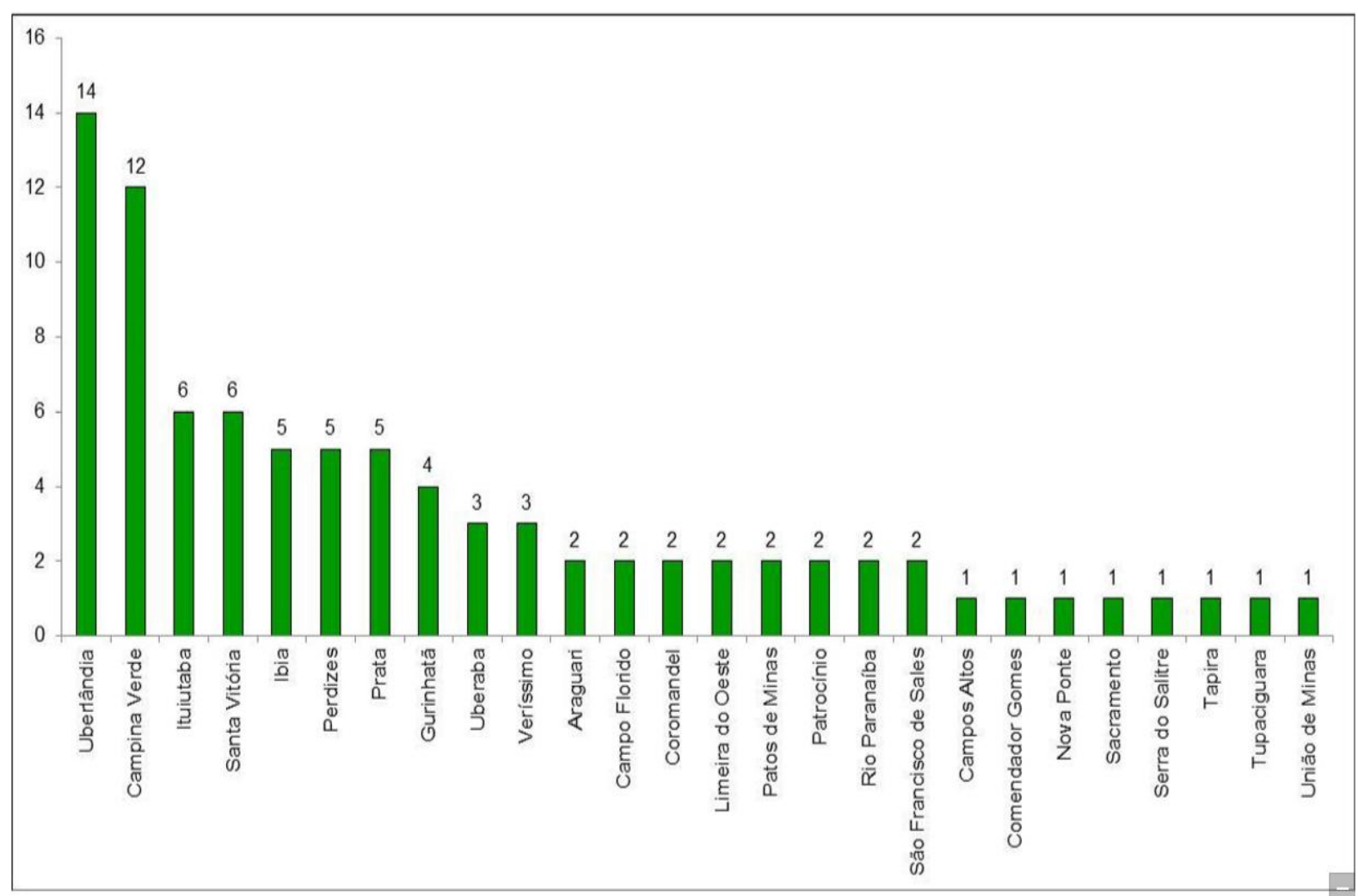

Fonte: DATALUTA - Banco de Dados da Luta pela Terra, 2014.

Para além do relevante número de assentamentos e famílias no município de Uberaba-MG, há pelo menos 8 municípios do entorno, em um raio inferior à $200 \mathrm{~km}$, que possuem comunidades campesinas em assentamentos. Assim, pode-se afirmar que a Universidade também tem público e demandas específicas para este grupo excluído dos processos educacionais formais pela sua condição de vida no campo.

Adicionalmente, como o Triângulo Mineiro está localizado ao oeste do Estado e faz divisa com a região nordeste do Estado de São Paulo, apresentaremos alguns municípios desta região de São Paulo sob influência das redes do fluxo produtivo que caracterizam a ruralidade deste território. Para determinar demandas específicas para o curso de Licenciatura em Educação do Campo da Universidade Federal do Triângulo Mineiro, o critério utilizado foi selecionar dentre os municípios da região noroeste de São Paulo, aqueles que mais tiveram entrada de estudantes nos vestibulares das licenciaturas nos anos de 2014/2015. A seguir, na tabela 3, algumas características destes municípios, no que concerne as 
demandas formativas para profissionais da

Educação que atuam nesta região.

Tabela 3. Caracterização dos Municípios de São Paulo com matrículas na UFTM em 2014/2015.

\begin{tabular}{|c|c|c|c|c|c|}
\hline Município & $\begin{array}{c}\text { Estimativa } \\
\text { populacional } \\
\text { (Dou, 2014) }\end{array}$ & $\begin{array}{c}\mathrm{N}^{\circ} \text { de } \\
\text { docentes } \\
\text { Educacão } \\
\text { básica* }\end{array}$ & $\begin{array}{c}\% \text { docentes } \\
\text { na zona } \\
\text { rural* }\end{array}$ & $\begin{array}{c}\text { \% docentes } \\
\text { sem formação } \\
\text { superior } \\
\text { completa* }\end{array}$ & $\begin{array}{c}\% \text { docentes sem } \\
\text { formação } \\
\text { continuada }\end{array}$ \\
\hline Ribeirão Preto & 658.059 & 7.141 & 0,2 & 12,9 & 91,7 \\
\hline Franca & 339.461 & 3.825 & Q & 8,7 & 71 \\
\hline Araraquara & 224.304 & 2.386 & 2. & 9,5 & 87,9 \\
\hline São José do Rio Preto & 438.354 & 4.892 & 3,6 & 18,3 & 76 \\
\hline Igarapava & 29.549 & 299 & 21,9 & 8,4 & 81,6 \\
\hline Guaíra & 32.394 & 500 & 1 & 19,2 & 83,2 \\
\hline São Carlos & 238.958 & 3.128 & 3,3 & 14 & 71,2 \\
\hline $\begin{array}{c}\text { São Joaquim da } \\
\text { Barra }\end{array}$ & 49.690 & 527 & Q & 6,5 & 75,7 \\
\hline Sertãozinho & 118.864 & 1.419 & 1 & 6,7 & 79,3 \\
\hline
\end{tabular}

Fontes: Estimativa populacional - DQU, 2014. Dados sobre os docentes: Cultiveduca (2016). Disponível em: http://cultiveduca.ufrgs.br/

A formação de professores e a realidade das escolas do campo no Triângulo Mineiro e Alto Paranaíba

Em levantamentos realizados pelo Instituto Nacional de Estudos e Pesquisas Educacionais Anísio Teixeira (INEP, 2007) podemos encontrar dados que indicam, ainda hoje, que a atuação de professores leigos no Brasil, isto é, sem a formação básica necessária, se dá, sobremaneira, nas escolas rurais. Além disso, muitas vezes, os professores atuantes, mesmo com o ensino superior completo, não receberam uma formação que reconhecesse as particularidades das escolas do campo e que tivessem um compromisso político com a formação das classes trabalhadoras. Sendo assim, muitas vezes a prática docente acaba por reproduzir visões que dialogam pouco com a realidade dos alunos oriundos do campo, acabando por desvalorizá-la e depreciá-la. 
Predomina uma atuação que não contribui para uma educação necessária para a autonomia da classe trabalhadora e requerida por este grupo social, pois a prática docente não está engajada em promover uma relação entre os conhecimentos científicos e a existência social e individual dos educandos e que permita a construção de conhecimentos para a leitura crítica da realidade social.

De acordo com o Censo Escolar de 2015, no Brasil são 98.503 professores leigos (sem formação em nível de ensino superior). A região Sudeste contempla 51.158 de professores leigos, sendo que destes 11.744 encontram-se no Estado de Minas Gerais. Considerando o Triângulo Mineiro e o Alto Paranaíba, a principal região atendida pela UFTM, há uma demanda de 1.397 professores leigos (INEP, 2015).

A preocupação com a formação inicial e continuada faz parte de diferentes políticas públicas nacionais e estaduais. $\mathrm{O}$ Estado de Minais Gerais instituiu em 2015 as Diretrizes para a Educação Básica nas escolas do campo de Minais Gerais (Minas Gerais, 2015), o que exige um repensar e um ressignificar da escola do campo e seus pressupostos políticos-pedagógicos.

Visando sistematizar e fortalecer a política pública de educação do campo no Estado, no ano de 2016 a Coordenação de
Educação do Campo da SEE/MG realizou uma sistematização das escolas do campo estaduais de Minas Gerais para fomentar implementação de políticas públicas da educação do campo, em concordância com as Diretrizes Operacionais para a Educação Básica nas Escolas do Campo (Brasil, 2002). Segundo tal documento, a Escola do Campo é aquela situada em área rural, conforme definida pela Fundação Instituto Brasileiro de Geografia e Estatística IBGE ou aquela situada em área urbana, desde que atenda, predominantemente, às populações do campo, conforme inciso II, do artigo $2^{\circ}$ da Resolução SEE No 2820 , de 11 de dezembro de 2015, ou seja, 50\% mais 1 do total dos estudantes matriculados sejam provenientes da zona rural.

Neste contexto, a partir do ano de 2017 as Superintendências de Ensino do Estado de Minas Gerais são orientadas a promover formação e incentivos para as escolas consideradas do campo, a se apropriarem dos fundamentos da educação do campo, se reconhecerem enquanto escola do campo e se for o caso, se utilizarem da Pedagogia da Alternância enquanto referencial pedagógico e metodológico, organizando o currículo e os tempos e espaços da formação básica. Neste contexto, a formação continuada de professores em atuação em escolas do 
campo passa a ser mais uma demanda da Licenciatura em Educação do Campo.

A região do Triângulo Mineiro e Alto Paranaíba, a partir da nova caracterização das escolas do campo balizada na Resolução SEE Nº 2820, de 11 de dezembro de 2015, passa a ter 19 escolas estaduais classificadas como sendo do campo, de acordo com dados da SEEMG de 2016 (Tabela 4).

Tabela 4. Escolas do Campo por município da região do Triângulo Mineiro e Alto Paranaíba, ano 2016.

\begin{tabular}{|c|c|c|c|c|c|}
\hline & Município & Escola & Local & $\begin{array}{l}\text { Total } \\
\text { Aluno }\end{array}$ & $\begin{array}{l}\text { Total Alunos } \\
\text { Residentes em } \\
\text { Zona Rural }\end{array}$ \\
\hline 1 & Araguari & EE Artur Bemardes & Distrito & 254 & 139 \\
\hline 2. & Campina Verde & EE Olinda Correa Borges & Distrito & 296 & 166 \\
\hline 3. & Coromandel & EE Padre Lázaro Menezes & Distrito & 126 & 79 \\
\hline 4 & Coromandel & EE Joaquim José De Assunção & Distrito & 230 & 156 \\
\hline 5. & Frutal & EE Presidente Tancredo Neves & Rural & 211 & 81 \\
\hline 6 & Guarinhatã & EE Heitor José De Castro & Distrito & 128 & 86 \\
\hline 7 & Irai de minas & EE São José Do Barreiro & Rural & 54 & 54 \\
\hline 8 & Itapagipe & EE Serra Da Moeda & Rural & 43 & 43 \\
\hline 2 & Lagoa formosa & EE José Marciano Brandão & Distrito & 124 & 85 \\
\hline 10 & Patos de minas & EE Agrotécnica Afonso Queiroz & Rural & 131 & 10 \\
\hline 11 & Patrocínio & EE Dona Cotinha & Rural & 135 & 130 \\
\hline 12 & Patrocínio & $\begin{array}{l}\text { EE de Ensino Fundamental E } \\
\text { Médio }\end{array}$ & Rural & 221 & 156 \\
\hline 13 & Patrocínio & $\begin{array}{l}\text { EE Coronel Elmiro Alves Do } \\
\text { Nascimento }\end{array}$ & Distrito & 364 & 272 \\
\hline 14 & Patrocínio & EE Yenina Tavares Amaral & Rural & 390 & 144 \\
\hline 15 & Perdizes & EE Horácio Afonso & Rural & 88 & 86 \\
\hline 16 & Perdizes & EE Josefa Margarida Trindade & Rural & 232 & 225 \\
\hline 17 & Uberaba & EE Aloizio Castanheira & Distrito & 130 & 125 \\
\hline 18 & Uberaba & EE Pro fessor Minervino Cesarino & Urbana & 165 & 156 \\
\hline 19 & Uberlândia & EE Mário Quintana & Rural & 112 & 93 \\
\hline
\end{tabular}

Fonte: SEE-MG/2016

Além de escolas propriamente consideradas do campo, há as chamadas escolas anexas ou escolas de segundo endereço. Conforme Decreto $n^{\circ} 7.352$, de 4 de novembro de 2010 (s.p/2016).
Art. $1^{\circ}$ A política de educação do campo destina-se à ampliação e qualificação da oferta de educação básica e superior às populações do campo, e será desenvolvida pela União em regime de colaboração com os Estados, o Distrito Federal e os Municípios, de acordo com as diretrizes e metas estabelecidas no 
Plano Nacional de Educação e o disposto neste Decreto. $\S 1^{\circ}$ Para os efeitos deste Decreto, entende-se por: I - Populações do campo: os agricultores familiares, os extrativistas, os pescadores artesanais, os ribeirinhos, os assentados e acampados da reforma agrária, os trabalhadores assalariados rurais, os quilombolas, os caiçaras, os povos da floresta, os caboclos e outros que produzam suas condições materiais de existência a partir do trabalho no meio rural; e

II - Escola do campo: aquela situada em área rural, conforme definida pela Fundação Instituto Brasileiro de Geografia e Estatística - IBGE, ou aquela situada em área urbana, desde que atenda predominantemente a populações do campo.

$\S 2^{\circ}$ Serão consideradas do campo as turmas anexas vinculadas a escolas com sede em área urbana, que funcionem nas condições especificadas no inciso II do $\S 10$.

Neste contexto legal, a partir de dados da SEE/MG foi possível identificar um total de 12 escolas anexas (Tabela 5), isto é, escolas que estão inseridas enquanto parte de escolas urbanas que atendem turmas compostas por populações predominantemente rurais. $\mathrm{O}$ principal público dos segundos endereços é aqueles da Educação de Jovens e Adultos.

Tabela 5. Escolas do Campo do Triângulo e Alto Paranaíba presentes em segundo endereço.

\begin{tabular}{|c|c|c|c|}
\hline Escola & SRE & Município & $\begin{array}{c}\text { Total de Segundo } \\
\text { Endereço }\end{array}$ \\
\hline 1 EE PEDRO ÁLVARES CABRAL & $\begin{array}{l}\text { SRE MONTE } \\
\text { CARMELO }\end{array}$ & $\begin{array}{l}\text { ABADIA DOS } \\
\text { DOURADOS }\end{array}$ & 1 \\
\hline EE LOREN RIOS FERES & SRE UBERABA & ARAXA & 1 \\
\hline EE VICENTE MACEDO & SRE UBERABA & FRUTAL & 1. \\
\hline $\begin{array}{l}\text { 4. EE CORONEL JOSE AFONSO DE } \\
\text { ALMEIDA }\end{array}$ & SRE UBERABA & SACRAMENTO & 2. \\
\hline 5. EE PROFESSOR CHAVES & SRE UBERABA & UBERABA & 1 \\
\hline EE QUINTILIANO JARDIM & SRE UBERABA & UBERABA & 1. \\
\hline $\begin{array}{l}\text { EE FREI LEOPOLDO DE } \\
\text { CASTELNUOVO }\end{array}$ & SRE UBERABA & UBERABA & 3. \\
\hline $\begin{array}{c}\text { 8. EE PROFESSOR JOSE IGNÁCIO } \\
\text { DE SOUSA }\end{array}$ & $\begin{array}{c}\text { SRE } \\
\text { UBERLANDIA }\end{array}$ & UBERLANDIA & 1 \\
\hline EE TEOTÔNIO VILELA & $\begin{array}{c}\text { SRE } \\
\text { UBERLANDIA }\end{array}$ & UBERLANDIA & 1 \\
\hline
\end{tabular}

Fonte: SEE-MG/2016.

Além disso, a sistematização das escolas do campo no âmbito do sistema de ensino estadual, cumpre destacar que há escolas do campo sob responsabilidade do governo municipal. Neste sentido, podemos notar uma expressiva quantidade de escolas municipais do campo localizadas nos municípios do Triângulo Mineiro e Alto Paranaíba, um total de 132 escolas do campo (Tabela 6). 
Tabela 6. Escolas do campo municipais no Triângulo Mineiro e Alto Paranaíba.

\begin{tabular}{|c|c|c|c|c|}
\hline $\mathbf{A}$ & $\mathbf{B}$ & $\mathbf{C}$ & $\mathbf{D}$ & $\mathbf{E}$ \\
\hline & Município & $\begin{array}{c}\text { Quantidade de } \\
\text { escolas Municipais } \\
\text { do Educação Básica } \\
\text { situadas em zona } \\
\text { rural }\end{array}$ & $\begin{array}{c}\text { Número de } \\
\text { docentes na zona } \\
\text { rural }\end{array}$ & $\begin{array}{l}\text { \% em relação ao } \\
\text { total de docentes } \\
\text { do município }\end{array}$ \\
\hline 1 & ABADIA DOS DOURADOS & 3 & 15 & 31,9 \\
\hline 2 & ÁGUA COMPRIDA & 0 & --- & --- \\
\hline 3 & ARAGUARI & 5 & 55 & 19,6 \\
\hline 4 & ARAPORÃ & 0 & --- & --- \\
\hline 5 & ARAPUÁ & 0 & --- & --- \\
\hline 6 & ARAXÁ & 5 & 57 & 12,2 \\
\hline 7 & CACHOEIRA DOURADA & 0 & --- & --- \\
\hline 8 & CAMPINA VERDE & 2 & 27 & 28,4 \\
\hline 9 & CAMPO FLORIDO & 2 & 9 & 13,4 \\
\hline 10 & CAMPOS ALTOS & 1 & 5 & 4,9 \\
\hline 11 & CANÁPOLIS & 2 & 4 & 6,3 \\
\hline 12 & CAPINÓPOLIS & 0 & --- & --- \\
\hline 13 & CARMO DO PARANAÍBA & 7 & 17 & 11 \\
\hline 14 & CARNEIRINHO & 2 & \multicolumn{2}{|c|}{$* *$} \\
\hline 15 & CASCALHO RICO & 0 & --- & --- \\
\hline 16 & CENTRALINA & 0 & --- & --- \\
\hline 17 & COMENDADOR GOMES & 0 & --- & --- \\
\hline 18 & $\begin{array}{l}\text { CONCEIÇÃO DAS } \\
\text { ALAGOAS }\end{array}$ & 0 & --- & --- \\
\hline 19 & CONQUISTA & 0 & --- & --- \\
\hline 20 & COROMANDEL & 4 & 14 & 9,9 \\
\hline 21 & CRUZEIRO DA FORTALEZA & 0 & --- & --- \\
\hline 22 & DELTA & 0 & --- & --- \\
\hline 23 & DOURADOQUARA & 0 & --- & --- \\
\hline 24 & ESTRELA DO SUL & 3 & 5 & 14,3 \\
\hline 25 & FRONTEIRA & 0 & --- & --- \\
\hline 26 & FRUTAL & 4 & 83 & 32,3 \\
\hline 27 & GRUPIARA & 0 & --- & --- \\
\hline 28 & GUIMARÂNIA & 2 & 4 & 8,7 \\
\hline 29 & GURINHATÃ & 1 & 3 & 9,4 \\
\hline 30 & IBIÁ & 5 & 38 & 21,8 \\
\hline 31 & INDIANÓPOLIS & 2 & 26 & 31,7 \\
\hline 32 & IPIAÇU & 0 & --- & --- \\
\hline 33 & IRAÍ DE MINAS & 0 & --- & --- \\
\hline 34 & ITAPAJIPE & 1 & \multicolumn{2}{|c|}{$* *$} \\
\hline 35 & ITUIUTABA & 5 & 50 & 10,5 \\
\hline 36 & ITURAMA & 1 & 16 & 7,9 \\
\hline
\end{tabular}

\begin{tabular}{|l|l|l|l|l|l|l|l|}
\hline Rev. Bras. Educ. Camp. & Tocantinópolis & v. 2 & n. 1 & p. 411-435 & jan./jun. & 2017 & ISSN: 2525-4863 \\
\hline
\end{tabular} 


\begin{tabular}{|c|c|c|c|c|}
\hline 37 & LAGOA FORMOSA & 0 & --- & --- \\
\hline 38 & LIMEIRA DO OESTE & 1 & 10 & 18,9 \\
\hline 39 & MATUTINA & 1 & 14 & 41,2 \\
\hline 40 & MONTE ALEGRE DE MINAS & 4 & 47 & 33,6 \\
\hline 41 & MONTE CARMELO & 4 & 38 & 32,8 \\
\hline 42 & NOVA PONTE & 1 & \multicolumn{2}{|c|}{$* *$} \\
\hline 43 & PATOS DE MINAS & 7 & 84 & 13,3 \\
\hline 44 & PATROCÍNIO & 6 & 75 & 22,5 \\
\hline 45 & PEDRINÓPOLIS & 0 & --- & --- \\
\hline 46 & PERDIZES & 4 & 12 & 11,4 \\
\hline 47 & PIRAJUBA & 0 & --- & --- \\
\hline 48 & PLANURA & 0 & --- & --- \\
\hline 49 & PRATA & 3 & 37 & 32,2 \\
\hline 50 & PRATINHA & 0 & --- & --- \\
\hline 51 & RIO PARANAÍBA & 6 & 14 & 17,5 \\
\hline 52 & ROMARIA & 0 & --- & --- \\
\hline 53 & SACRAMENTO & 7 & 57 & 39 \\
\hline 54 & SANTA JULIANA & 0 & --- & --- \\
\hline 55 & SANTA ROSA DA SERRA & 2 & 17 & 53,1 \\
\hline 56 & SANTA VITÓRIA & 2 & 20 & 17,9 \\
\hline 57 & SÃO FRANCISCO DE SALES & 0 & --- & --- \\
\hline 58 & SÃO GOTARDO & 1 & 2 & 1,5 \\
\hline 59 & SERRA DO SALITRE & 3 & 11 & 18 \\
\hline 60 & TAPIRA & 1 & 10 & 12,7 \\
\hline 61 & TIROS & 2 & 5 & 13,9 \\
\hline 62 & TUPACIGUARA & 3 & 29 & 19,6 \\
\hline 63 & UBERABA & 6 & 187 & 10,6 \\
\hline 64 & UBERLÂNDIA & 10 & 318 & 9,6 \\
\hline 65 & UNIÃO DE MINAS & 0 & --- & --- \\
\hline 66 & VERÍSSIMO & 1 & 6 & 26,1 \\
\hline \multicolumn{3}{|c|}{$\begin{array}{l}\text { * Coluna C = FONTE DE DADOS: MINAS GERAIS. } \\
\text { Assembleia Legislativa. Diretoria de Processo Legislativo. } \\
\text { Gerência-Geral de Consultoria Temática. Fonte primária: } \\
\text {. Secretaria de Estado de Educação. Relação de } \\
\text { Estabelecimentos de Ensino (ativos), segundo a } \\
\text { Superintendência Regional de Ensino, o município, a } \\
\text { dependência administrativa e a localização, por etapa, } \\
\text { nível e modalidade de ensino. Belo Horizonte, 2013. } \\
\text { Disponível } \\
\text { https://www.educacao.mg.gov.br/images/stories/escolas/20 } \\
\text { 13lista_de_escolas/03_lista_escolas.xls Acesso em: } 27 \text { mar. } \\
\text { 2013. } \\
\text { ** não constam professores na zona rural na plataforma } \\
\text { consultada }\end{array}$} & \multicolumn{2}{|c|}{$\begin{array}{l}* \text { Colunas D e E }=\text { Fonte de dados site } \\
\text { CultivEduca. Dados referentes apenas à } \\
\text { rede municipal de ensino. }\end{array}$} \\
\hline
\end{tabular}

Como é possível notar, a região do caracterização de campo a ser considerada, entorno da UFTM possui expressiva assim como escolas do campo que 
precisam receber atenção de profissionais que possuam a formação em educação do campo, o que é fundamental para a materialização desta perspectiva de educação, em concordância com o Decreto $n^{\circ} 7.352$, de 4 de novembro de 2010 (s.p/2016).

$\S \quad 4^{\circ}$ A educação do campo concretizar-se-á mediante a oferta de formação inicial e continuada de profissionais da educação, a garantia de condições de infraestrutura e transporte escolar, bem como de materiais e livros didáticos, equipamentos, laboratórios, biblioteca e áreas de lazer e desporto adequados ao projeto políticopedagógico e em conformidade com a realidade local e a diversidade das populações do campo.
Ademais, é importante considerar o perfil de formação dos docentes que atuam na zona rural que indicam a necessidade de formação em nível superior. De acordo com a base de dados Cultiveduca (Carvalho, Neves, \& Melo, 2016) 12,50\% dos docentes da região do Triângulo Mineiro e Alto Paranaíba atua na zona rural (1448 de um total de 11.213). Sendo que, do total de docentes da região 17,4\% não possuem formação de ensino superior, o que é reforçado pelo Censo Escolar 2015, conforme já destacado anteriormente (Tabela 7).

Tabela 7 Formação inicial dos docentes da região do Triângulo Mineiro e Alto Paranaíba

\begin{tabular}{cccccc}
\hline \multicolumn{5}{c}{ Formação inicial dos docentes (referente ao número total 11213) } \\
\hline $\begin{array}{c}\text { Ens. Fundamental } \\
\text { incompleto }\end{array}$ & $\begin{array}{c}\text { Ens. Fundamental } \\
\text { completo }\end{array}$ & $\begin{array}{c}\text { Ens. Médio } \\
\text { normal/magistério }\end{array}$ & $\begin{array}{c}\text { Ens. Médio } \\
\text { completo }\end{array}$ & $\begin{array}{c}\text { Superior } \\
\text { Incompleto }\end{array}$ & $\begin{array}{c}\text { Superior } \\
\text { Completo }\end{array}$ \\
4 & $\&$ & 1380 & 183 & 374 & 9260 \\
$\mathbf{0} \%$ & $0,10 \%$ & $12,30 \%$ & $1,60 \%$ & $3,30 \%$ & $82,60 \%$ \\
\hline
\end{tabular}

Fonte: (Carvalho, Neves, \& Melo, 2016). Cultiveduca.

\section{Considerações finais}

A Licenciatura em Educação do Campo traz muitos desafios para a Universidade e, principalmente, para os docentes que estão engajados na sua realização. A questão dos conteúdos a serem ensinados e as metodologias a serem usadas, devem estar diretamente atreladas à realidade de seus alunos, ao desafio de uma formação crítica para a modificação da atual educação que é urbanocêntrica.

A concepção da educação do campo almeja outro projeto de sociedade que se contrapõe ao atual neoliberal, exploratório e degradante. Amplia-se a preocupação pedagógica. Passa-se a olhar um pouco 
mais para os territórios de abrangência da formação que se almeja. Territórios que necessitam de demarcação e que esta demarcação se faça com parâmetros que superem o urbanocentrismo. Assim, é preciso compreender sua composição, seus modos de vida, suas contradições. Este olhar permeado pela práxis é fundamental para que a Universidade Pública consiga contemplar sua responsabilidade social com os sujeitos do campo que são os que mais sofrem com os fechamentos das escolas do campo e nucleação em escolas urbanas, com quilômetros e quilômetros percorridos por crianças até a escola na cidade, com a baixa formação de seus professores e etc.

Neste contexto, esperamos que este trabalho possa delimitar melhor o cenário em que a Licenciatura em Educação do Campo da UFTM vem trabalhando e ajudar a fortalecer sua relevância no cenário regional, até mesmo para dar norte a tantas outras demandas que são suprimidas pelo olhar que exclui o rural em suas diferentes expressões.

\section{Referências}

Araujo, R., \& Chelotti, L. (2013). Geografia da Educação do Campo no Triângulo Mineiro. Revista Histedbr, 226237.
Brasil. (03 de Abril de 2002). Resolução CNE/CEB 1, De 3 De Abril de 2002. Brasília. Acesso em 2017, disponível em http://portal.mec.gov.br/component/docma n/?task=doc download\&gid=13800\&Itemi $\underline{\mathrm{d}}$

Caldart, R. S. (2009). Educação do Campo: Notas para uma análise de percurso. Trabalho, Educação e Saúde, 7(1), 35-64.

Carvalho, J., Neves, B., \& Melo, R. (2016). Cultiveduca. Rio Grande do Sul, Brasil. Acesso em 2016, disponível em http://cultiveduca.ufrgs.br/pg.index.html

Girardi, E. P. (2015). DATALUTA Banco de Dados da Luta pela Terra: Relatório Brasil 2014. Presidente Prudente, São Paulo, Brasil.

Haesbaert, R. (2005). Região, diversidade territorial e globalização. Rio de Janeiro, Rio de Janeiro, Brasil. Fonte: http://www.uff.br/geographia/ver_01/Roge rio\%Haesbaert.pdf

Instituto Brasileiro de Geografia e Estatística. (2015). Fundação IBGE Instituto Brasileiro de Geografia. Acesso em 2017, disponível em IBGE: http://www.ibge.gov.br/home/geociencias/ geografia/default_regioes_rurais.shtm

Instituto Brasileiro de Geografia e Estatística. (2015). Instituto Brasileiro de Geografia e Estatística. Fonte: IBGE: http://www.ibge.gov.br/home/geociencias/ geografia/default_regioes_rurais.shtm

Instituto Nacional de Estudos e Pesquisas Educacionais Anísio Teixeira (INEP). (2007). Panorama da educação no campo. Brasília, Distrito Federal, Brasil. Fonte: http://www.publicacoes.inep.gov.br/portal/ download/546

Instituto Nacional de Estudos e Pesquisas Educacionais Anísio Teixeira (INEP). 
(2015). Censo Escolar 2015. Acesso em 2017. Disponível em: http://portal.inep.gov.br/web/guest/censoescolar

Minas Gerais. (20 de Dezembro de 2015). Resolução SEE $\mathrm{N}^{\circ}$ 2820, De 11 de Dezembro de 2015. Institui as Diretrizes para a Educação Básica nas escolas do campo de Minas Gerais. Belo Horizonte, Minas Gerais, Brasil. Acesso em 2017, disponível em https://www.educacao.mg.gov.br/images/d ocumentos/Diretrizes\%20da\%20Educa\%C 3\%A7\%C3\%A3o\%20do\%20Campo\%20d o\%20Estado\%20de\%20Minas\%20Gerais.p df

Santos, C., Paludo, C., \& Oliveira, R. (2010). Concepção de educação do campo. Em C. Taffarel, \& et. al. Cadernos didáticos sobre educação no campo (pp. 13-65). Salvador: Editora UFBA.

Valadares, A. A. (2014). O gigante invisível: território e população rural para além das convenções oficiais. Brasília. Acesso em 2017, disponível em: http://repositorio.ipea.gov.br/bitstream/110 58/2866/1/TD_1942.pdf

Veltz, P. (1999). Zonas, polos, rede: la economia de archipiélago. Em P. Veltz, Mundialização, ciudades y Territorios - la economia de archipiélago. (pp. 53-65). Barcelona: Ariel.

Recebido em: 09/03/2017

Aprovado em: 03/04/2017

Publicado em: 29/06/2017
Como citar este artigo / How to cite this article / Como citar este artículo:

APA:

Souza, D. C., Kato, D. S., \& Pinto, T. H. O. (2017). A licenciatura em Educação do Campo na Universidade Federal do Triângulo Mineiro: território de contradições. Rev. Bras. Educ. Camp., 2(1), 411-435.

DOI:

http://dx.doi.org/10.20873/uft.2525-

4863.2017v2n1p419

ABNT:

SOUZA, D. C.; KATO, D. S.; PINTO, T. H. O. A licenciatura em Educação do Campo na Universidade Federal do Triângulo Mineiro: território de contradições. Rev. Bras. Educ. Camp., Tocantinópolis, v. 2, n. 1, p. 411-435, 2017. DOI: http://dx.doi.org/10.20873/uft.25254863.2017v2n1p419 